PAPER

\title{
Is mandatory research ethics reviewing ethical?
}

\author{
Murray Dyck, ${ }^{1}$ Gary Allen ${ }^{2}$
}

${ }^{1}$ Griffith University, School of Applied Psychology, Gold Coast, Queensland, Australia ${ }^{2}$ Research Office, Griffith University, Brisbane, Queensland, Australia

\section{Correspondence to} Dr Murray Dyck, Griffith University, School of Applied Psychology, Gold Coast, Queensland 4222, Australia; m.dyck@griffith.edu.au

Accepted 10 July 2012

\section{ABSTRACT}

Review boards responsible for vetting the ethical conduct of research have been criticised for their costliness, unreliability and inappropriate standards when evaluating some non-medical research, but the basic value of mandatory ethical review has not been questioned. When the standards that review boards use to evaluate research proposals are applied to review board practices, it is clear that review boards do not respect researchers or each other, lack merit and integrity, are not just and are not beneficent. The few benefits of mandatory ethical review come at a much greater, but mainly hidden, social cost. It is time that responsibility for the ethical conduct of research is clearly transferred to researchers, except possibly in that small proportion of cases where prospective research participants may be so intrinsically vulnerable that their well-being may need to be overseen.

As the reach of Institutional Review Boards (IRBs; aka Research Ethics Committees, Institutional Ethics Committees, Human Research Ethics Committees) has increased, ${ }^{1}$ so have complaints about the cost of obtaining approval for research from IRBs in terms of time, ${ }^{2}$ money ${ }^{3-5}$ and lost opportunity. ${ }^{6}$ Complaints have been made about the unreliability of IRB decisions, which has become more evident as the volume of multisite research has increased. Different IRBs assessing the same application come to different decisions and impose different, sometimes conflicting, requirements on researchers who may need to placate hundreds of IRBs. ${ }^{7}$ There is evidence ${ }^{9}$ that what IRBs sometimes require researchers to do can distort and compromise the research. The situation has not been helped by the fact that there is no published casework of precedents for IRB judgments and no timely, efficient, or trustworthy means to appeal IRB decisions. ${ }^{10}$ Finally, IRBs have been criticised for applying a biomedical model of research ethics and procedure that is inappropriate to other research fields, including ethnography, anthropology and sociology, ${ }^{11} 12$ sometimes overriding the guidelines being developed in those fields. ${ }^{13}$ Strangely, what has not been questioned is whether mandatory ethical reviews of research proposals are appropriate in any research field and whether this review actually provides useful outcomes.

IRBs were conceived in response to a few wellknown horrific breaches of human rights that were largely committed by medical researchers. These breaches included the infamous medical experiments conducted on Nazi concentration camp inmates by Josef Mengele at Auschwitz and Erwin Ding-Shuler at Buchenwald, but also observational studies of African-American men with syphilis who were not treated when effective treatments became available $e^{14}$ and a wide range of medical and mind-control experiments on healthy American prison inmates who were recruited by means of cash inducements and special privileges. ${ }^{10}$ Also, psychological and social science projects such as Milgram's obedience experiment, Humphrey's 'Tearoom Trade' study and Zimbardo's Stanford prison experiment generated scandal and calls for the regulation of research. These studies continued into the 1970s until the principles of research on human subjects were codified in the Belmont Report and the vetting of research proposals by IRBs was made mandatory.

The main approach to regulating human research ethics has two key characteristics: the prior review of all human research by an IRB and the use of prescriptive one-size-fits-all rules to all human research. Even though most jurisdictions now have special review arrangements for negligible and low risk projects, those arrangements have much in common with the standard IRB review, albeit with less paperwork and faster reviews. Critically, the conduct of these expedited reviews use the same standards and expectations as the standard IRB review. This standard approach is based on three assumptions: (1) that it is possible to use centrally mandated rules to direct complex behaviour that occurs in extremely varied, and sometimes fluid, contexts ${ }^{15}$; (2) that it is reasonable and useful to impose controls conceived in response to scandal to regulate the behaviour of a well-intentioned community (ie, researchers); and (3) that the use of enforcement and sanctions will catch dangerous research and in so doing protect the rights and welfare of participants and minimise institutional risk. But has the ethics bureaucracy that has evolved as a defence against scandal provided an effective safeguard against researchers who, through negligence, arrogance or indifference, place participants in harm's way, and has this benefit been worth the cost?

Since the introduction of mandatory IRB reviews, there have been very few serious examples of the abuse of research participants' rights by researchers. In the most sobering cases (eg, the death of Jessie Gelsinger in a gene therapy trial at University of Pennsylvania and the death of a healthy volunteer, Ellen Roche, in an experimental study of asthma at Johns Hopkins University ${ }^{16-18}$ ), researchers were judged, among other failings, to have provided insufficient information about the risks of participation in the research, including the serious side effects that had affected other participants, the death of animals 
(monkeys) from the treatment, and implying that a chemical to be administered to participants was known to be safe when it had been reported to have toxic effects. The two studies had been approved by IRBs, and both studies point to flaws in the IRB model.

The first flaw is that IRBs need to rely on the accuracy of information provided to them by researchers because they cannot have or reasonably obtain the expertise necessary to verify the veracity of all the information provided to them. ${ }^{19}$ Ironically, the IRB system presupposes the intellectual competence and ethical integrity of applicants to provide the comprehensive, understandable, and balanced information necessary to evaluate whether the proposal complies with ethical guidelines. It also assumes that researchers can predict how their planned research will progress, what participants will experience and what ethical challenges will arise in the field. Especially for disciplines like anthropology, such assumptions are not only misguided, they can result in decisions that are inappropriately conservative, compromise valuable research and perpetuate a culture of resistance. ${ }^{13}$ The second flaw is that the IRB model encourages researchers to 'outsource' ethical responsibility for their work to one or more IRBs rather than to accept responsibility for the ethical conduct of their work. ${ }^{20}$ Gaining clearance from an IRB is perceived as an administrative hurdle-like gaining funding, or gatekeeper approval to recruit participants, or other regulators' approvals to use a pharmaceutical or device-that needs to be overcome in order to conduct the research. The attention of researchers is focussed on what needs to be done to satisfy an IRB-about which an IRB will ultimately provide explicit instructions-rather than on appreciating the ethical implications of their research and ensuring that ethical principles are adhered to throughout the research endeavour.

The IRB model is inherently flawed, but the way IRB procedures have developed, it is now also the case that mandatory IRB review procedures would not themselves reach the ethical standard expected of researchers. These standards include respect for persons, merit and integrity, justice and beneficence.

Respect for Persons: Mandatory review is a clear failure to show respect for persons (researchers) because it presupposes that researchers cannot be trusted to design and implement research that respects the rights of participants unless researchers are made accountable to an IRB to do so (even though IRB procedures also presuppose the ethical integrity of the applications for ethical approval). Disrespect for researchers is also shown by delays in processing applications (up to 445 days ${ }^{21}$ ) and by the failure to provide clear guidelines on what is expected of researchers. ${ }^{22}$

Merit and Integrity: Mandatory multiple reviews of multisite research indicate that IRBs do not trust the merit and integrity of other IRBs and their failure to accept the judgment of other IRBs shows disrespect for other IRBs' members. If institutions require their own IRB reviews as part of a risk management or governance process, the merit of the ethical review process is at risk of being confounded by extraneous considerations. The merit and integrity of IRB processes is also brought into doubt by the frequency and extent of inconsistent outcomes when multisite research undergoes multiple reviews: it is a truism in measurement and assessment that lack of reliability indicates lack of validity. There is evidence that this problem is being responded to in many jurisdictions by setting up new procedures to facilitate single site review of multisite research, but to date the granting of approval based on prior review by another IRB appears to be a rare event.
Justice: IRBs often place what, at face value, is an unfair burden on researchers. Humphreys et al ${ }^{4}$ estimated that the cost of eight supplementary IRB reviews (after the research had been approved by their own institution's IRB) was \$56 191 in 2001 US dollars. They also concluded that the nine reviews, which involved the exchange of 15000 pages of documents, had 'no discernible impact on human subjects protection' (p. 77). Maskell et $a l^{21}$ found that following approval by a multi-centre review committee, gaining approval from 51 local IRBs involved 25296 pieces of paper, $62 \mathrm{~h}$ of photocopying, and $3.27 \mathrm{~h}$ of investigator time per submission. Tully et al ${ }^{23}$ required the approval of 125 local committees, which involved 105888 pieces of paper and delays exceeding 36 weeks that caused the loss of $17 \%$ of potential participants recruited to the study during the delay period. Between 2000 and 2007, there were many horror stories about the inappropriate delays, demands, and lost opportunities to social sciences researchers caused by IRBs. ${ }^{13}$ It is beyond doubt that the burden in time, money, trees and inconvenience is a great one, but whether it is unfair depends on whether the benefits of the review process exceed the burden imposed.

Beneficence: Do the benefits of mandatory IRB reviews outweigh the costs? Williams ${ }^{19}$ identified three benefits of IRB reviews: they provide oversight of the rights of research participants, they symbolise society's concern about research ethics, and they have focussed the attention of scientists on research ethics. In our experience, oversight of the rights of research participants routinely enhances the quality and breadth of information provided to participants and occasionally enhances the way researchers engage with participants, but rarely prevents ethically dubious research from proceeding. The reason why unethical research is rarely prevented is that unethical research protocols are rarely submitted for approval. This might be taken as evidence that IRB oversight is an effective way of ensuring the ethical conduct of research, but we think that it is more likely that contemporary researchers, like the overwhelming majority of their predecessors, have sufficient awareness of and engagement with ethical principles and practices, and sufficient understanding of the consequences of unethical practices, to ensure that their research is conducted ethically. In the main, the few protocols where participants' rights are not adequately protected tend to be the work of student researchers who have managed to get their proposals submitted for review without the approval of their supervisors. Otherwise, we suspect that the small set of researchers who disregard the welfare and rights of research participants either do not take their work near an IRB or, if they do, they misrepresent their work so as to appear to comply with the letter of ethical research practice.

Although there is minimal empirical evidence that the oversight provided by IRBs is effective in protecting research participants from human rights abuse, there is clear evidence that IRB reviews impose tangible costs on society that greatly exceed even the costs in time and money that are expended in complying with IRB procedures. Whitney and Schneider ${ }^{24}$ estimated the number of deaths that resulted from delays in gaining IRB approvals to conduct the Second International Study of Infarct Survival study, a 'randomised trial of intravenous streptokinase, oral aspirin, both, or neither among 17187 cases of suspected acute myocardial infarction'. ${ }^{25}$ Trial results indicated that all treatments, but especially the combined treatment, reduced mortality by up to $42 \%$. Whitney and Schneider estimated that an 8 month delay in gaining IRB approval to conduct this research would have resulted in between about 
3600 and 20500 deaths, depending on what assumptions are made about how quickly study results were disseminated and applied in practice. To our knowledge, the total number of deaths that have resulted from all delayed medical trials has not been estimated, but it must be a frighteningly large number.

A second hidden cost to society that results from mandatory IRB review is the number of investigations that never occur, or the number of potential investigators who decline to participate in research, as a result of the cost in time and money to gain IRB approval. Glasziou and Chalmers ${ }^{8}$ noted that no randomised treatment trials were conducted during the severe acute respiratory syndrome (SARS) epidemic in part because there was insufficient time to gain IRB approval. All timelimited research, including student research, research being conducted by researchers on fixed-term contracts, and pilot research that needs to be completed prior to a deadline for applying for research funds, is made less feasible by delays in obtaining IRB approval. Researchers who are time-limited regularly report changing the nature of the research they conduct in order to increase the chance of obtaining rapid IRB approval or in order to avoid the need for IRB review. ${ }^{6}$ Yawn et a ${ }^{26}$ found that medical practitioners declined to participate in practicebased research network studies because previous experience had shown that complying with the requirements of IRBs was too time-consuming and onerous.

It has been suggested that the creation of the IRB system and the extension of this system to cover all human research reflected a 'moral panic' that was precipitated by a very small number of very significant violations of the human rights of research participants. ${ }^{12}$ It now appears that the IRB 'cure' has proved more deadly than the disease of unethical research, and that there is an urgent need to construct more effective and efficient ways of preserving those benefits that do flow from ethics reviews. Our suggestions as to how oversight of the rights of research participants can be maintained, how society's concern about research ethics can be symbolised, and how the attention of scientists on research ethics can be enhanced are presented below.

Shift in role: Instead of promoting rote compliance with inflexible and universal rules, the role of an IRB should be to facilitate and resource the reflective practice of researchers. A simple, but significant, shift would be to move ethical review from approving a proposed project to providing guidance and feedback on submitted projects. An IRB may play a useful role in identifying ethical issues and suggesting how to deal with them, but otherwise, responsibility for research ethics needs to return to the researchers who use the feedback they receive in a reflective and project-appropriate way. Rather than policing compliance with standards that can have limited usefulness for some methods, participant populations and contexts, such an advisory review would aim to assist researchers in reflecting on the specific ethical challenges of their research. The best way to safeguard the welfare and rights of participants, and to protect the interests of researchers' host institutions, is for ethically principled research to be recognised as a hallmark of research that is professional, well-designed, well-conducted, and of high quality.

Emulate the practice of the health professions, which embrace professional codes of ethics to which members of the profession are expected to adhere and where adherence is assumed unless there are allegations and evidence to the contrary. Just as with the professional codes for the health professions, a research code should be embedded in professional practice and applied during the actual conduct of research. There may be cases where prior ethical review should be mandated, such as in the case of research with specific vulnerable groups (possibly including prisoners, refugees, persons not capable of providing consent, unborn foetuses, and dispossessed cultural groups) and specific areas of research (including work intended to expose illegal behaviour), even though experience indicates that ethics committees have been hyper-sensitive to the potential for controversy in work with such groups and this sensitivity has been a significant source of delay and other problems. ${ }^{13}$ Even then there are potential difficulties in assuming the experience of such participant groups is homogenous or that every individual is powerless and vulnerable to exploitation by an unwitting or unscrupulous researcher. Another practical problem is the degree to which such individuals may be coincidentally present in general populations. For this reason, the criteria for mandated prior review must be relevant to the full range of research disciplines and designs, and at least equal resources should be invested in fostering, supporting and resourcing the reflective practice of researchers. Where review is mandatory, proportionate review should be conducted by a single designated IRB (eg, Correctional Services IRB) and should be focussed upon advising and supporting, not regulatory enforcement.

Where ethical review is mandated by a funding agency and funding is conditional upon such review, the review should be conducted by an IRB nominated by the funding agency and the cost of review should be fully funded.

Where ethical review is mandated by a gatekeeper, the review should be conducted by a single designated IRB (eg, National Institutes of Health IRB).

Any other research is exempt from ethical review: Researchers can be assisted to identify whether an IRB review is mandated (eg, if participants belong to a vulnerable group) and to selfassess and categorise the risks. In practice, and to avoid the self-defeating requirement to submit requests for exemption from IRB review for IRB review, ${ }^{13}$ there need to be simple and efficient mechanisms that allow researchers to self-assess whether, and what form of, proportional review may be appropriate. The primary role of institutional agencies should be to advise and to facilitate discourse on ethical challengesnot to review, 'clear' or 'approve' research. The role of ethics review is to provide feedback and propose strategies to researchers, not to approve the research. The responsibility of how to apply that feedback and conduct the work ethically rests with the researchers. Where the risks to participants are greater than negligible, researchers should lodge information about how the rights of participants are to be protected with their IRB and this information should be publicly available. There should be resources available to assist researchers during the planning, conduct, analysis and reporting of results. Institutions should establish networks of research ethics advisors-colleagues who can be approached for advice and support. Where review is required, the processes should be proportional to the ethical sensitivity of the specific project, be relevant for the discipline and research design, and operate with the objective of facilitating excellence in research, not enforcing compliance. The review process should be an advisory and collegial one-not one that focuses on compliance, enforcement and gatekeeping.

\section{REFERENCES}

1. Borenstein J. The expanding purview: Institutional Review Boards and the review of human subjects research. Account Res 2008;15:188-204.

2. Gold JL, Dewa CS. Institutional Review Boards and multisite studies in health services research: is there a better way? Health Serv Res 2005;40:291-307. 
3. Byrne MM, Speckman J, Getz K, et al. Variability in the costs of Institutional Review Board oversight. Acad Med 2006;81:708-12.

4. Humphreys K, Trafton J, Wagner TH. The cost of Institutional Review Board procedures in multicenter research. Ann Int Med 2003;139:77.

5. Ravina B, Deuel L, Siderowf A, et al. Local Institution Review Board review of a multicenter trial: local costs without local context. Ann Neurol 2010; 67:258-60.

6. Barzilai G, Gallagher W, Harrington C, et al. The impact of Institutional Review Boards (IRB) on law and society researchers. Report of the Membership and Professional Issues Committee to the Board of Trustees of the Law and Society Association, 2007, July 24, 2007, Berlin. http://www.lawandsociety.org/ LSA MPIC Report.pdf (accessed 13 Jul 2010)

7. Dziak K $\mathbf{K}$ Anderson R, Sevick MA, et al. Variations among Institutional Review Board reviews in a multisite health services research study. Health Serv Res 2005; $40: 279-90$

8. Glasziou P, Chalmers I. Ethics review roulette: what can we learn? BMJ 2004;328:121-2

9. Israel M. Ethics and the governance of criminological research in Australia. Sydney, NSW: Report for the New South Wales Bureau of Crime Statistics and Research, 2004.

10. Yanow D, Schwartz-Shea P. Reforming Institutional Review Board policy: issues in implementation and field research. PS, 2008;July, 483-94.

11. Lincoln VS, Tierney WG. Qualitative research and Institutional Review Boards. Qual Inq 2005; 10:219-34.

12. van den Hoonaard WC. Is research-ethics review a moral panic? CRSA/RCSA 2001;38:19-36.

13. Schrag ZM. Ethical imperialism: institutional review boards and the social sciences, 1965-2009. Baltimore, MD: Johns Hopkins University Press, 2010.

14. Schweder R. Tuskegee re-examined. 2004. http://www.spiked-online.com/Articles/ 0000000CA34A.htm (accessed 16 Aug 2011).
15. Allen G. Getting beyond form filling: the role of institutional governance in human research ethics. J Acad Eth 2008;6:105-16.

16. Education Development Center. The Ellen Roche case: Research with healthy volunteers. Exploring bioethics. 2009. science.education.nih.gov/supplements/nih9/ bioethics/guide/pdf/Master 5-3.pdf (accessed 15 Jul 2010).

17. FDA. Alkis Togias, M.D./Johns Hopkins Asthma \& Allergy Clinic, Baltimore, MD. FDA 483 Inspectional Observations (Baltimore) 06/28/2001. http://www.fda.gov/ AboutFDA/CentersOffices/ORA/ORAElectronicReadingRoom/ucm064082.htm (accessed 15 Jul 2010).

18. Greenberg DS. Science for sale: the perils, rewards, and delusions of campus capitalism. Chicago, IL: University of Chicago Press, 2007.

19. Williams PC. Success in spite of failure: why IRBs falter in reviewing risks and benefits. IRB: Eth Hum Res 1984;6:1-4.

20. Derbyshire S. Unethical committees. 2005. http://www.spiked-online.com/index. php?/site/article/625/. (accessed 16 Aug 2011).

21. Maskell NA, Jones EL, Davies RJO. Variations in experience in obtaining local ethical approval for participation in a multi-centre study. Quart J Med 2003;96:305-7.

22. Kozanczyn C, Collins K, Fernandez CV. Offering results to research subjects: U.S. Institutional Review Board policy. Account Res 2005;14:255-67.

23. Tully J, Vinis N, Booy R, et al. The new system of review by multi-centre research ethics committees: prospective study. BMJ 2000;320:1179-82.

24. Whitney SN, Schneider CE. Viewpoint: a method to estimate the cost in lives of ethics board review of biomedical research. J Int Med 2010;269:392-406.

25. ISIS-2 (Second International Study of Infarct Survival) Collaborative Group. Randomised trial of intravenous streptokinase, oral aspirin, both, or neither among 17187 cases of suspected acute myocardial infarction. Lancet 1988;332:349-60.

26. Yawn BP, Graham DG, Bertram SL, et al. Practice-based research network studies and Institutional Review Boards: two new issues. J Am Bd Fam Med 2009;22:453-60 
JME

\section{Is mandatory research ethics reviewing ethical?}

Murray Dyck and Gary Allen

$J$ Med Ethics published online August 3, 2012

doi: 10.1136/medethics-2011-100274

Updated information and services can be found at:

http://jme.bmj.com/content/early/2012/08/02/medethics-2011-100274.full.html

\section{These include:}

References This article cites 17 articles, 3 of which can be accessed free at: http://jme.bmj.com/content/early/2012/08/02/medethics-2011-100274.full.html\#ref-list-1

$\mathbf{P}<\mathbf{P} \quad$ Published online August 3, 2012 in advance of the print journal.

Email alerting Receive free email alerts when new articles cite this article. Sign up in service the box at the top right corner of the online article.

\begin{tabular}{|c|c|}
\hline Topic & Articles on similar topics can be found in the following collections \\
\hline & $\begin{array}{l}\text { Research and publication ethics ( } 345 \text { articles) } \\
\text { Prison medicine ( } 24 \text { articles) } \\
\text { Human rights ( } 98 \text { articles) } \\
\text { Sexual health ( } 98 \text { articles) }\end{array}$ \\
\hline
\end{tabular}

Notes

Advance online articles have been peer reviewed, accepted for publication, edited and typeset, but have not not yet appeared in the paper journal. Advance online articles are citable and establish publication priority; they are indexed by PubMed from initial publication. Citations to Advance online articles must include the digital object identifier (DOIs) and date of initial publication.

To request permissions go to:

http://group.bmj.com/group/rights-licensing/permissions

To order reprints go to:

http://journals.bmj.com/cgi/reprintform

To subscribe to BMJ go to:

http://group.bmj.com/subscribe/ 